\title{
Catalytic Activity of Tetrahydrobiopterin in Dihydropteridine Reductase Deficiency and Indications for Treatment
}

\author{
ALBERTO PONZONE. ORNELLA GUARDAMAGNA. IRMA DIANZANI. RICCARDO PONZONE. \\ GIOVANNI BATTISTA FERRERO, MARCO SPADA, AND RICHARD G. H. COTTON \\ Departmemt of Pediatrics, University of Torino, 10126 Torino, Italy /A.P., O.G., I.D., R.P., G.B.F., M.S./: and \\ Olive Miller Lahoratory. Murdoch Institute, Royal Children's Hospital, Parkville, Australia 3052, [R.G.H.C.]
}

\begin{abstract}
It is now widely accepted that tetrahydrobiopterin (BH4), the natural cofactor of aromatic amino acid hydroxylases, in the absence of its regenerating enzyme dihydropteridine reductase (DHPR), will function only stoichiometrically in the phenylalanine (Phe) hydroxylating system. This has limited the use of pterin cofactor in diagnosis and treatment of patients suffering from inherited DHPR deficiency, one of the most common forms of hyperphenylalaninemia caused by $\mathrm{BH} 4$ deficiency. This is despite the observation of a dramatic fall in serum Phe concentration after $\mathrm{BH} 4$ loading in such patients. In this study, quantitation of this phenomenon was obtained by comparing the kinetics of serum Phe after either a simple Phe or a combined Phe plus BH4 oral loading in patients with Phe hydroxylase or with DHPR deficiency. Only in the latter was the total body clearance of Phe enhanced up to 5 times by the cofactor administration, resulting in the molar equivalent of Phe hydroxylated/mol of $\mathrm{BH} 4$ ranging from at least 6 to 10, against the postulated 1. As a consequence, BH4 administration should be attempted therapeutically in DHPR-deficient patients, thus avoiding a lifelong Phe-restricted diet. Preliminary experience with such treatment is given with two cases. (Pediatr Res 33: 125-128, 1993)
\end{abstract}

\section{Abbreviations}

BH4, tetrahydrobiopterin

DHPR, dihydropteridine reductase

Phe, phenylalanine

PKU, phenylketonuria

qBH2, quinonoid dihydrobiopterin

TBC, total body clearance

Trp, tryptophan

Tyr, tyrosine

BH4 is the essential cofactor of Phe, Tyr, and Trp hydroxylases. After a coupled reaction with these enzymes, $\mathrm{BH} 4$ is oxidized to $\mathrm{qBH} 2$. Regeneration of $\mathrm{BH} 4$ from the $\mathrm{qBH} 2$ derivative is catalyzed by DHPR (EC 1.66.99.7)(1). In humans. DHPR deficiency is one of the causes of hyperphenylalaninemia caused by defects in $\mathrm{BH} 4$ metabolism (2). It has been accepted that the total absence of DHPR activity will restrict $\mathrm{BH} 4$ to function only stoichiometrically in the Phe hydroxylating system. thus mini-

Received March 31. 1992; accepted September 2, 1992.

Correspondence and reprint requests: Dr. R.G.H. Cotton. Murdoch Institute. Royal Children's Hospital. Flemington Road, Parkville. Victoria, Australia 3052.

Supported by the National Health and Medical Research Council of Australia. mizing the potential value of cofactor administration in the treatment of patients (2-5). This belief has been held despite the early demonstration of a dramatic lowering of serum Phe by an i.v. dose of $2 \mathrm{mg} / \mathrm{kg}$ BH4 in DHPR deficiency (6) and despite more recent observations that such patients show a similar response when given an oral loading test with $5-20 \mathrm{mg} / \mathrm{kg} \mathrm{BH} 4$ (7-10). Further support for the hypothesis that $\mathrm{BH} 4$ is acting catalytically was raised by the effects of $\mathrm{BH} 4$ in a DHPR-deficient child (11), which were not consistent with a simple stoichiometric conversion of Phe.

We have therefore used simple Phe loading and combined Phe plus $\mathrm{BH} 4$ loading to determine the spontaneous and the cofactorinduced Phe hydroxylating activity in PKU and DHPR-deficient patients. As exogenous BH4 increased the hydroxylation rate of Phe only in the latter, it was possible to quantitate the catalytic activity of cofactor in DHPR deficiency by estimating the molar equivalent of Phe hydroxylated/mol of administered BH4. This finding was subsequently confirmed by treating the two DHPRdeficient patients with synthetic cofactor after the Phe-restricted diet had been stopped.

\section{MATERIALS AND METHODS}

Patient selection. The study population consisted of four patients, aged 16 mo to 7 y (three males and one female). Data are shown in Table 1. Three were identified as hyperphenylalaninemic through the neonatal mass screening for PKU, and the fourth (M.P.), who was previously reported (12), was identified at the age of $10 \mathrm{mo}$. The diagnosis was subsequently defined through the administration of an oral BH4 loading test (13) coupled with a blood spot test for DHPR activity assay (14). Two patients (M.P., M.B.) had an ultimate diagnosis of DHPR deficiency "nonresponding" to cofactor administration (15); the other two (S.Z., F.M.) were diagnosed as having PKU, with a mild phenotype according to their Phe tolerance (16). Patients Phe tolerance was determined just before the study and defined as the maximal amount of dietary Phe they could ingest while keeping serum Phe levels below $480 \mu \mathrm{mol} / \mathrm{L}$. The two PKU patients were selected for this study because they had a Phe tolerance value close to that of DHPR-deficient patients (Table 1).

Phe and BH4 loading tests. L-Phe was obtained from Merck. Rathway, NJ, and BH4 (6RS-L-erythro-BH4 dihydrochloride) from Dr. Schirks Laboratory, Wettswill, Switzerland. A simple oral Phe $(100 \mathrm{mg}=605 \mu \mathrm{mol} / \mathrm{kg})$ loading test and a combined oral Phe $(100 \mathrm{mg} / \mathrm{kg})$ and $\mathrm{BH} 4(20 \mathrm{mg}=63.66 \mu \mathrm{mol} / \mathrm{kg})$ loading test were performed in all patients under good dietary control (basal serum Phe ranging from 47 to $261 \mu \mathrm{mol} / \mathrm{L}$ ) after an overnight fast. The two DHPR-deficient patients also had a combined loading test with the same amount of Phe but with the dose of $7.5 \mathrm{mg}(23.07 \mu \mathrm{mol}) / \mathrm{kg} \mathrm{BH} 4$. In each case. $\mathrm{BH} 4$ was 
Table 1. Details of patients with PKU and with DHPR deficiency (DHPR $\left.{ }^{-}\right)$

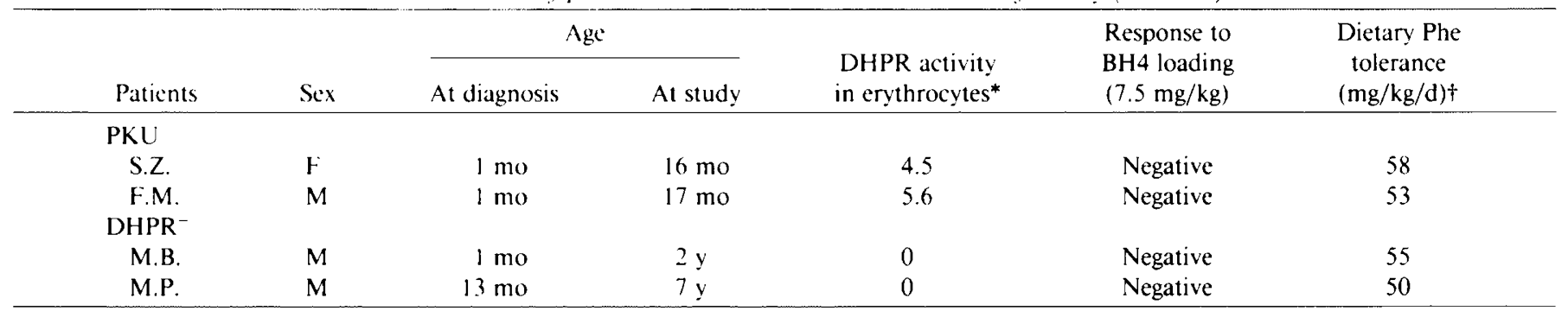

* nmol cytochrome c reduced/min/5-mm diameter filter paper disc.

† Maximal dietary intake of Phe as required to maintain serum Phe concentration below $480 \mu \mathrm{mol} / \mathrm{L}$.

administered $3 \mathrm{~h}$ after loading with Phe, as preliminary tests (unpublished observations) had shown that all patients reached serum peak levels of Phe within this time. During the tests, patients received a Phe-restricted diet, with a daily intake of Phe matching the individual tolerance. Serum Phe and Tyr concentrations were measured by the Kontron Chromakon 500 automatic analyzer at different intervals before and during the tests. The Phe kinetics was evaluated in the $27-\mathrm{h}$ interval after Phe loading by calculating the TBC as dose of Phe administered divided by area under serum Phe concentration. Following the classic trapezoidal rule, the area under serum Phe concentration was obtained from the sum of different trapezia arising from two contiguous concentration values and the respective time interval. The portion of the area from the last concentration value $\left(C_{t}\right)$ and infinity was evaluated as $C_{t} / K$, where $K$ is the elimination constant (17). The elimination rate of Phe from serum was calculated in the 3 to 11 -h interval after Phe loading as velocity $(\mu \mathrm{mol} / \mathrm{L} / \mathrm{h})$ and as a percentage of the Phe loading dose. The increase in serum Phe elimination rate eventually obtained in the same patient during the above interval with the combined Phe plus $\mathrm{BH} 4$ loading test. as compared with the simple Phe loading test. was computed as the rate of BH4-promoted Phe hydroxylation. On this basis, it was also possible to estimate the amount of Phe administered that had been hydroxylated by the exogenous cofactor in the 3- to 11-h interval after Phe loading and to approximate the molar ratio between this amount and the dose of administered $\mathrm{BH} 4$.

Continuous BH4 therapy: Monotherapy with synthetic cofactor was attempted in the two DHPR-deficient patients (M.B. and M.P.. Table 1). Since diagnosis, they had been on standard treatment, receiving a Phe-restricted diet, folinic acid $(15 \mathrm{mg} / \mathrm{d})$, and neurotransmitter precursors (L-dopa and 5-OH-Trp. $5 \mathrm{mg} /$ $\mathrm{kg} / \mathrm{d}$. plus carbidopa. $1 \mathrm{mg} / \mathrm{kg} / \mathrm{d}$ ). In contrast to the case of $\mathrm{BH} 4$ synthesis defects. where the complete integrity of cofactor recycling allows it to be administered in a single daily dose. $20 \mathrm{mg} /$ $\mathrm{kg} / \mathrm{d}$ BH 4 were administered in four divided doses, i.e., $5 \mathrm{mg} / \mathrm{kg}$ $20 \mathrm{~min}$ before every meal. Neurotransmitter therapy was stopped, and diet was rapidly liberalized. When patients were on a free diet. the daily Phe intake, calculated a posteriori, fluctuated between 110 and $150 \mathrm{mg} / \mathrm{kg}$, thus overcoming the individual Phe tolerance by up to $100 \mathrm{mg} / \mathrm{kg}$.

The response to $\mathrm{BH} 4$ monotherapy was evaluated both clinically, by watching the appearance of symptoms of biogenic amine deficiency, and biochemically, by measuring the serum Phe and the cerebrospinal fluid homovanillic and 5-hydroxyindole acetic acid concentrations.

\section{RESULTS}

The results of the different Phe and $\mathrm{BH} 4$ loading tests are shown in Table 2. With the simple Phe loading test, the time course of change of serum Phe concentration was similar in PKU and in DHPR-deficient patients, as was the TBC of Phe (range: $0.023-0.027 \mathrm{~L} / \mathrm{kg} / \mathrm{h}$ ). The administration of $\mathrm{BH} 4$ resulted in unchanged TBC of Phe in PKU patients, whereas in DHPRdeficient patients. it increased consistently and in a linear manner with the dose of administered cofactor: by 2.5 times with 7.5 $\mathrm{mg} / \mathrm{kg}$ and by 5 times with $20 \mathrm{mg} / \mathrm{kg}$. DHPR-deficient patients halved Phe serum peak levels with $7.5 \mathrm{mg} / \mathrm{kg}$ and reverted them to basal values with $20 \mathrm{mg} / \mathrm{kg} \mathrm{BH} 4$ within $11 \mathrm{~h}$ after Phe loading. Thus, the overall Phe serum elimination rate and the $\mathrm{BH}_{4}$ promoted serum Phe hydroxylation rate were evaluated in the 3- to 11-h interval. The administration of $\mathrm{BH} 4$ resulted in unchanged serum elimination rate of the Phe load in PKU patients as compared with the simple Phe loading, whereas in DHPR-deficient patients the elimination rate increased in terms of both velocity and percentage of the Phe loading dose, by 2fold with the dose of $7.5 \mathrm{mg} / \mathrm{kg}$ and by 3-fold with the dose of $20 \mathrm{mg} / \mathrm{kg} \mathrm{BH} 4$. Although $\mathrm{BH} 4$ administration did not induce any elimination of the Phe load in PKU patients, in DHPRdeficient patients, the rate of Phe eliminated increased consistently and linearly with the doses of administered cofactor. This elimination could not be by any mechanism other than hydroxylation. The estimated molar ratio of the amount of serum Phe hydroxylated in the 3- to $11-\mathrm{h}$ interval to the amount of $\mathrm{BH} 4$ administered ranged in DHPR-deficient patients from 5.57 to 8.88. If conversion was stoichiometric, a ratio of 1 would be expected (Table 2). Serum Tyr concentrations consistently increased in the DHPR-deficient patients and slightly increased in one PKU patient after the combined Phe plus $\mathrm{BH} 4$ loading test (data not shown). However, serum Tyr fluctuations did not appear to be clearly dose- and time-related to $\mathrm{BH} 4$ administration.

Preliminary results from the treatment of patients were consistent with these experimental findings. At the time of this writing (February 1992), M.B. had been on BH4 monotherapy for $1 \mathrm{y}$. Serum Phe levels were constantly in a harmless range $(<240 \mu \mathrm{mol} / \mathrm{L})$. The concentration of cerebrospinal fluid biogenic amine metabolites decreased with the discontinuation of neurotransmitter therapy. On diet plus neurotransmitter therapy. homovanillic acid and 5-hydroxyindole acetic acid were 168 and $125 \mathrm{nmol} / \mathrm{L}$, respectively. After $12 \mathrm{mo}$ on continuous $\mathrm{BH} 4$ therapy $(20 \mathrm{mg} / \mathrm{kg})$, the values were 126 and $7 \mathrm{nmol} / \mathrm{L}$, respectively (age-matched controls $300-800$ and $100-300 \mathrm{nmol} / \mathrm{L}$, respectively). In the absence of symptoms, it was judged safe to avoid restarting neurotransmitter therapy, as clinical symptoms of biogenic amine deficiency appear within a few hours when the exogenous supply is inadequate or the endogenous production is severely impaired (Ponzone A, unpublished observations). Further, the irreversible brain damage in DHPR deficiency seems due to either hyperphenylalaninemia or folate depletion rather than neurotransmitter deficiency (18).

Due to the limited $\mathrm{BH} 4$ availability, M.P. has been on BH4 monotherapy only for $1 \mathrm{mo}$. Also, in this patient the hyperphenylalaninemia could be fully corrected, but the early fall of the concentrations of homovanillic and 5-hydroxyindole acetic acid in cerebrospinal fluid together with the appearance of neurologic symptoms required resumption of neurotransmitter therapy.

\section{DISCUSSION}

By analyzing the time course of changes in serum Phe concentrations in PKU and DHPR-deficient patients alternately loaded 
Table 2. Loading tests with Phe' and with Phe + BH4 in PKL' and DHPR-deficient (DHPR') patients*

\begin{tabular}{|c|c|c|c|c|c|c|c|c|c|c|c|c|c|}
\hline \multirow[b]{5}{*}{ Paticnts } & & & \multirow{2}{*}{$\frac{\text { Phe }}{0}$} & \multicolumn{2}{|l|}{$\mathrm{BH} 4$} & \multicolumn{7}{|c|}{ Time after Phe loading $(\mathrm{h})$} & \multirow[b]{2}{*}{$3-11$} \\
\hline & & & & 3 & 7 & 11 & 27 & $0-27$ & & & & & \\
\hline & \multirow{2}{*}{\multicolumn{2}{|c|}{$\begin{array}{l}\text { Loading } \\
\text { dose } \\
(\mathrm{mg} / \mathrm{kg})\end{array}$}} & \multirow{3}{*}{\multicolumn{5}{|c|}{$\begin{array}{l}\text { Serum Phe concentration } \\
\qquad(\mu \mathrm{mol} / \mathrm{L})\end{array}$}} & \multirow{3}{*}{$\begin{array}{l}\text { Phe TBC } \\
(\mathrm{L} / \mathrm{kg} / \mathrm{h})\end{array}$} & \multicolumn{2}{|c|}{ Serum Phe elimination } & \multicolumn{2}{|c|}{$\begin{array}{c}\text { Serum Phe } \\
\text { hydroxylation }\end{array}$} & \multirow{3}{*}{$\begin{array}{l}\text { Molar ratio } \\
\text { (hydroxylated Phe: } \\
\text { administered } \mathrm{BH} 4 \text { ) }\end{array}$} \\
\hline & & & & & & & & & Velocity & $\%$ of & Velocity & $\%$ of & \\
\hline & Phe & $\mathrm{BH} 4$ & & & & & & & $(\mu \mathrm{mol} / \mathrm{L} / \mathrm{h})$ & load dose & $(\mu \mathrm{mol} / \mathrm{L} / \mathrm{h})$ & load dose & \\
\hline S.Z. & 100 & 20 & 80 & 736 & 604 & 512 & 304 & 0.039 & 15.5 & 20.5 & 0 & 0 & 0 \\
\hline \multirow[t]{2}{*}{ F.M. } & 100 & & 116 & 934 & 620 & 684 & 408 & 0.027 & 31.2 & 41.3 & & & \\
\hline & 100 & 20) & 261 & 10.37 & 892 & 764 & 590 & 0.026 & 34.1 & 45.1 & 2.9 & 3.8 & 0.36 \\
\hline \multicolumn{14}{|l|}{$\mathrm{DHPR}^{-}$} \\
\hline M.B. & 100 & & 127 & 1026 & 965 & 828 & 468 & 0.026 & 24.7 & 32.7 & & & \\
\hline \multirow{2}{*}{ M.P. } & 100 & 7.5 & 74 & 744 & 451 & 386 & 148 & 0.072 & 44.7 & 59.2 & 19.5 & 25.8 & 5.57 \\
\hline & 100 & 20 & 47 & 710 & 327 & 122 & 80 & 0.13 & 73.5 & 97.2 & 48.5 & 63.8 & 6.06 \\
\hline
\end{tabular}

* All patients had a simple Phe oral loading and a combined Phe $+\mathrm{BH} 4$ oral loading with the higher cofactor dose (20 mg/kg). The two DHPR patients also had a combined loading with a cofactor dose of $7.5 \mathrm{mg} / \mathrm{kg}$. The tests were performed after an overnight fast. and patients were kept on a restricted dietary Phe intake. thus allowing calculation of the TBC of the administered Phe. The elimination rate of serum Phe was determined in the 3- to 11-h interval after Phe loading. The rate of Phe hydroxylation induced by $\mathrm{BH} 4$ administration in the same interval resulted from the difference between the serum elimination rate after the combined and after the simple loading test. The molar equivalent of Phe hydroxylated in the 3- to 11 -h interval per mol of administered $\mathrm{BH} 4$ was then calculated.

with only Phe and with $\mathrm{BH} 4$ in addition to Phe, we demonstrated that six to 10 times more Phe is hydroxylated/mol of administered cofactor in DHPR deficiency than is expected from the equimolar ratio (3-5). BH4 administration to $\mathrm{PKU}$ patients served as a control to ensure that the resulting decrease in Phe levels in DHPR deficiency was due solely to hydroxylation and not to incorporation into bound pools, transamination, or decarboxylation. Alternate loading of DHPR-deficient patients with only Phe and with Phe plus BH4 also allowed us to compute the rate of hydroxylation of the Phe load that was only dependent on exogenous cofactor activity.

There are at least two $\mathrm{BH} 4$ loading-response classes of DHPR deficiency. In some patients, the hyperphenylalaninemia can be corrected by giving $7.5 \mathrm{mg} / \mathrm{kg} \mathrm{BH} 4$, whereas other patients fail to respond to this load but do respond to $20 \mathrm{mg} / \mathrm{kg} \mathrm{BH} 4(8-10$, 15). As DHPR-deficient patients of only the latter type are included in this study, it can be argued that, in patients belonging to the first class, the molar ratio of Phe hydroxylated to the administered $\mathrm{BH} 4$ might be an additional three times higher. Moreover. in this study, calculations were made by assuming the full availability of the administered $\mathrm{BH} 4$, though previous studies have shown that the absolute bioavailability of exogenous $\mathrm{BH} 4$. mainly because of the limited gut absorption. is as low as $6 \%$ (19). This could increase the rate of Phe converted $/ \mathrm{mol}$ of $\mathrm{BH} 4$ administered by an additional 15 times. resulting in an actual molar ratio of Phe to BH4 of at least 90:1. A possible threshold effect of BH4 within this therapeutic range is excluded, as the increase in the Phe hydroxylation rate was related, on a molar basis, to the administered cofactor dose. This observation also indicates that the dose of $20 \mathrm{mg} / \mathrm{kg}$ is not sufficient to saturate the body enzyme system in DHPR-deficient patients.

It is clear that $\mathrm{BH} 4$ recycling occurs in DHPR-deficient patients. Our findings, together with previous observations, raise a number of questions that cannot be satisfactorily answered at this time. Despite BH4 being detected in DHPR-deficient patients (20), it appears not to be used in hydroxylation of Phe. This could be due to the exogenously administered $\mathrm{BH} 4$ being somehow different from the endogenous $\mathrm{BH} 4$ demonstrated in patients. An NADPH-dependent DHPR has been detected (21). and it is not clear why this enzyme cannot take over when the NADH-dependent enzyme is absent. It is completely unclear what enzyme is responsible for recycling $\mathrm{qBH}_{2}$ in DHPR-deficient patients. The possibilities for this function include: $l$ ) dihydrofolate reductase with production of $\mathrm{BH} 4$ after the rearrangement of $\mathrm{qBH}_{2}$ to the 7.8 form, the substrate of this enzyme, which has been identified in DHPR deficiency (20); 2) 5.10 methylene tetrahydrofolate reductase. known to carry out the DHPR function (22): or 3) residual DHPR activity of the mutant enzyme.

Assays of DHPR in our patients' red blood cells and fibroblasts indicated "zero" activity. In fact, this means $<0.5 \%$ of normal activity. Considering that (discounting other routes) if DHPR was really zero the fetus may not be viable in utero, it is likely that there is some residual activity that cannot be accurately quantitated. Thus, if for example residual activity was $0.1 \%$ of normal, and considering the enzyme is ubiquitous, this may be sufficient for the recycling we observe. Ethical considerations prevent us from measuring liver DHPR to see if it is different from a level of $<0.5 \%$.

According to the previous belief that, in DHPR deficiency. BH4 will attain only stoichiometric conversion of Phe to Tyr. Kaufman $(3,4)$ has estimated that the prohibitively expensive dose of $70-120 \mathrm{mg} / \mathrm{kg} \mathrm{BH} 4 / \mathrm{d}$ would be needed simply to keep pace with the Phe hydroxylation reaction. According to the present findings, the above figure should be reduced by six to 10 times, corresponding to a daily dosage of $8-20 \mathrm{mg} / \mathrm{kg} \mathrm{BH} 4$. It should be noted that our patients were given an oral Phe load dose $(100 \mathrm{mg} / \mathrm{kg})$ exceeding the estimated daily Phe requirement in infants and children $(22-90 \mathrm{mg} / \mathrm{kg}$ ) (1) and approaching the mean daily Phe intake of children on a free diet. This figure was confirmed by preliminary patient studies, as continuous $\mathrm{BH} 4$ therapy at the dose of $20 \mathrm{mg} / \mathrm{kg} / \mathrm{d}$ allowed patients to stay on a free diet, with a daily Phe intake ranging between 110 and 150 $\mathrm{mg} / \mathrm{kg}$ compared with the basal Phe tolerance of $50-55 \mathrm{mg} / \mathrm{kg}$.

If exogenous $\mathrm{BH} 4$ can be used in DHPR deficiency to convert Phe to Tyr, it is likely that it will also be working in the Tyr and 
Trp hydroxylation reactions. However. due to the poor brain entry of synthetic cofactor (23), BH4 therapy might be ineffective in restoring sufficient dopamine and serotonin production at the central level. This is a critical point, because every DHPRdeficient patient should be carefully evaluated when BH4 monotherapy is attempted to determine if cofactor can be used simply to avoid a low Phe diet or also to help maintain adequate neurotransmitter levels.

Acknowledgments. The authors thank Drs. G. Thompson and H. Dahl for criticisms of the manuscript.

\section{REFERENCES}

1. Scriver CR, Kaufman S, Woo SLC 1989 The hyperphenylalaninemias. In: Scriver CR. Beaudet AL. Sly WS, Valle D (eds) The Metabolic Basis of Inherited Diseases. McGraw-Hill, New York, pp 495-546

2. Kaufman S. Holtzman NA, Milstein S, Butler IJ, Krumholz A, 1975 Phenylketonuria due to dihydropteridine reductase deficiency. $\mathrm{N}$ Engl $\mathrm{J}$ Med 293:785-789

3. Kaufman S 1975 Pterin administration as a therapy for P.K.U. due to dihydropteridine reductase deficiency? Lancet 2:767

4. Kaufman $S 1985$ Hyperphenylalaninemia caused by defects in biopterin metabolism. J Inherited Metab Dis 8(suppl 1):20-27

5. Kaufman S 1986 Unsolved problems in diagnosis and therapy of hyperphenylalaninemia caused by defects in tetrahydrobiopterin metabolism. J Pediatr 109:572-578

6. Danks DM. Cotton RGH, Schlesinger P 1975 Tetrahydrobiopterin treatment of variant forms of phenylketonuria. Lancet 2:1043

7. Niederwieser A, Matasovic A, Staudenman W, Wang M, Curtius H-Ch 1982 Screening of tetrahydrobiopterin deficiency. In: Watcher $\mathrm{H}$, Curtius $\mathrm{H}-\mathrm{Ch}$, Pfleiderer W (eds) Biochemical and Clinical Aspects of Pteridines, Vol 1. de Gruyter. New York, pp 293-306

8. Niederwieser A. Ponzone A. Curtius H-Ch 1985 Differential diagnosis of tetrahydrobiopterin deficiency. J Inherited Metab Dis(suppl 1):34-38

9. Ponzone A, Guardamagna O, Ferraris S, Bracco G, Cotton RGH 1987 Screening for malignant phenylketonuria. Lancet $1: 512-513$

10. Ponzone A. Guardamagna O. Ferraris S, Ferrero GB, Dianzani I. Cotton RGH 1991 Tetrahydrobiopterin loading test in hyperphenylalaninemia. Pediatr Res 30:435-438

11. Smith I, Hyland K. Kendall B 1985 Clinical role of pteridine therapy in tetrahydrobiopterin deficiency. J Inherited Metab Dis 8(suppl 1):39-45
12. Ponzone A. Guardamagna O. Ferraris S. Bracco G. Niederwieser A. Cotton RGH 1988 Two mutations of dihydropteridine reductase deficiency. Arch Dis Child 63:154-157

13. Niederwieser A, Curtius H-Ch, Wang M, Leupold D 1982 Atypical phenylketonuria with defective biopterin metabolism. Monotherapy with tetrahydrobiopterin or sepiapterin. screening and study of biosynthesis in man. Eur J Pediatr 138:110-112

14. Arai N, Narisawa K. Hayakawa H, Tada K 1982 Hyperphenylalaninemia due to dihydropteridine reductase deficiency: diagnosis by enzyme assay on dried blood spot. Pediatrics 70:426-430

15. Cotton RGH. Jennings I, Bracco G. Ponzone A. Guardamagna O 1986 Tetrahydrobiopterin non-responsiveness in dihydropteridine reductase deficiency is associated with the presence of mutant protein. J Inherited Metah Dis $9: 239-243$

16. Okano Y. Eisensmith RC. Guttler F. Lichter-Konecki U, Konecti DS. Treftz FK. Dasovich M, Wang T. Henriksen K. Lou H, Woo SLC 1991 Molecular basis of phenotypic heterogeneity in phenylketonuria. $\mathrm{N}$ Engl J Med 324:1232-1238

17. Gibaldi M, Perrier D 1975 Pharmacokinetics. Marcel Dekker Inc., New York

18. Ponzone A, Ferrero GB, Guardamagna O. Ferraris S 1989 Screening and treatment of tetrahydrobiopterin deficiency. Chemistry and Biology of Pteridines. Proceedings of the Ninth International Symposium on Pteridines and Folic Acid Derivatives: Chemical. Biological and Clinical Aspects. Zurich. Switzerland, pp 393-401

19. Ferraris S, Guardamagna O, Bonetti G. Bracco G. Leone L. Ponzone A 1987 Fate of peripheraily administered tetrahydrobiopterin in congenital tetrahydrobiopterin deficiency. In: Curtius H-Ch. Blau N. Levine RA (eds) Unconjugated Pterins and Related Biogenic Amines. de Gruyter, Berlin, pp 283292

20. Howells DW. Smith I, Leonard J, Hyland K 1986 Tetrahydrobiopterin in dihydropteridine reductase deficiency. N Engl J Med 314:520-521

21. Nakanishi N, Ozawa K, Yamada S 1986 Determination of NADPH-specific dihydropteridine reductase in extract from human, monkey, and bovine livers by single radial immunodiffusion: selective assay differentiating NADPH- and NADH-specific enzymes. J Biochem 99:1311-1315

22. Matthews RG, Kaufman S 1980 Characterization of the dihydropterin reductase activity of pig liver methylenetetrahydrofolate reductase. J Biol Chem 255:6014-6017

23. Ponzone A. Biasetti S, Ferraris S. Guardamagna O, Curtius H-Ch, Kierat I. Blau N 1989 Differential entrance of tetrahydrobiopterin into the brain of patients with 6-pyruvoyl tetrahydropterin synthase deficiency. In: Levine RA. Milstein S, Kuhn DM. Curtius $\mathrm{H}-\mathrm{Ch}$ (eds) Pteridines and Biogenic Amines in Neuropsychiatry, Pediatrics, and Immunology. Lakeshore Publishing Co., Grosse Pointe, MI, pp 325-334 